Currículo sem Fronteiras, v. 19, n. 3, p. 1339-1357, set./dez. 2019

\title{
LUGAR DOCENTE DE PSICOPATOLOGIA EM CURSOS DE PSICOLOGIA: biopolítica, governamentalidade e subjetividade
}

\author{
Conrado Neves Sathler \\ Universidade Federal da Grande Dourados - UFGD \\ Márcia Aparecida Amador Mascia \\ Universidade São Francisco - USF
}

\begin{abstract}
Resumo
A análise genealógica de uma amostra do lugar docente na disciplina de Psicopatologia de 51 cursos de Psicologia abrangendo, com acesso virtual, todas as regiões do país e Instituições de Ensino Superior públicas, privadas, confessionais e comunitárias permitiu apontar para a emergência de sujeitos voltados às demandas das Políticas Públicas das áreas de Saúde, Educação e Segurança, entre outras, e como suas produções acadêmicas se ligam a essas políticas. Permitiu também tocar sujeitos formadores em Psicologia engajados como profissionais em diversos campos de trabalho, lecionando no contraturno ou como professores de várias outras disciplinas que têm algo a dizer sobre a Psicopatologia. O objetivo foi buscar perceber as condições nas quais esses sujeitos emergem e como dispositivos biopolíticos os alcançam a serviço do govern(ament)o no controle das populações.
\end{abstract}

Palavras-chave: Educação Superior; Currículo; Formação em Psicologia; Psicopatologia; Subjetividade.

\begin{abstract}
The genealogical analysis of a sampling of the teaching position in the discipline of Psychopathology of 51 Psychology graduation courses covering, with virtual access, all regions of the country in the public, private, confessional and community college institutions, allowed to point to the emergence of subjects focused on the demands of Public Policies in the areas of Health, Education and Security, among others, and how their academic productions are linked to these policies. It has also allowed to touch subjects in Psychology who are engaged as professionals in different fields of work, teaching in the alternative turn, or as professors in various disciplines that have something to say about Psychopathology. The aim was to seek to understand the conditions in which these subjects emerge and how the biopolitical devices reach them at the service of the govern(ment) in the control of populations.
\end{abstract}

Keywords: College Education; Curriculum; Psychology Education; Psychopathology; Subjectivity.

ISSN 1645-1384 (online) www.curriculosemfronteiras.org 


\section{Introdução}

O texto que apresentamos é o resultado parcial de uma pesquisa docente sobre o ensino de Psicopatologia no país. Nosso objetivo, neste recorte, é discutir o ensino de Psicopatologia pela via da análise do lugar do professor e do papel dessa disciplina na racionalidade governamental de nossa sociedade. O que focamos, neste momento, é o lugar docente em Psicopatologia. Ao afirmar que o foco é o lugar docente queremos especificar a posição teórica sobre este objeto e como o alcançamos em nossas descrições e análises, a saber, pela perspectiva discursiva e com recursos da análise genealógica foucaultiana.

Desta forma, o trabalho é essencialmente qualitativo e os dados que compõem o corpus são documentais e públicos, não havendo qualquer identificação da amostragem. Os dados foram acessados pela rede mundial de computadores. A utilização dos gráficos se dá, neste contexto, apenas como instrumento auxiliar da descrição dos dados.

Inseridos em um conjunto de práticas que se repetem e, ao se repetirem, se legitimam, ou seja, inseridos em uma instituição (Guilhon Albuquerque, 1978, p. 70ss), os professores tomam parte de um agenciamento, desenvolvem uma espécie de mandato que os autoriza administrativamente a aprovar ou reprovar, em seu âmbito disciplinar restrito, os alunos em formação, permitindo ou não a progressão e a conclusão do processo educacional formativo. A autonomia do professor é limitada e para manter-se como agente institucional ele deve conservar-se obediente às regras institucionais: cumprir um plano de ensino aprovado, observar e inserir-se nas orientações do Projeto Pedagógico do Curso e seguir as normas para avaliar os alunos, além de atender às demais demandas próprias das relações pedagógicas e escolares como: ministrar aulas, atender alunos, participar de reuniões de planejamento, de avaliação e de administração escolar.

Essa institucionalização compõe a subjetividade da categoria dos professores em geral e especificaremos, a seguir, os atravessamentos mais comuns nas atividades docentes de Psicopatologia. Antes, porém, ressaltamos que o lugar institucional ocupado por esses professores é legitimado enquanto cumpridores de certo mandato. O reconhecimento de suas atividades como apropriadas está carregado de uma construção disciplinar histórica: é preciso ter autoridade para falar pela inserção em um discurso doutrinário em uma sociedade discursiva e, ainda, apresentar credenciais formais da titulação para ocupar o posto de professor (cf. FOUCAULT, 1996). Logo, nossas observações não dizem respeito ao indivíduo que ocupa este posto ou esta posição subjetiva. As condicionantes apresentadas indicam que, qual seja o ocupante desse lugar discursivo, os atravessamentos não sofrerão variações significativas.

Na perspectiva discursiva, o sujeito não é produtor ou origem de seu discurso, ao contrário, ele é um produto, um efeito dos discursos que o atravessam. Além disso, há uma linguagem, regras e práticas anteriores ao sujeito, uma cultura na qual o indivíduo se inscreve e nessa inscrição assume compromissos que o impelem a posições subjetivas inerentes àquele lugar. Ainda mais, concebemos o sujeito como um produto, uma bricolagem cujas diferenças individuais observadas decorrem de seus trajetos identitários, das histórias dos embates entre assujeitamento-resistência e das nuances políticas estabelecidas às instituições, dos 
compromissos assumidos pelos agentes privilegiados junto às comunidades interna e externa e pelos mandatários institucionais. Por fim, há um componente ético na formação identitária deste sujeito que responde ao que ele pensa de si e de seu trabalho. Compreendemos esses fatores como registros arqueológicos, genealógicos e éticos implicados na formação das subjetividades (Veiga-Neto, 2007).

Se os trabalhos de Foucault, na fase entendida como arqueológica, tematizam a episteme, ou seja, as regras de formação dos saberes no limiar do discurso (Foucault, 1995), pode-se dizer que a genealogia se apresenta, no desenrolar de suas pesquisas, a partir do seguinte questionamento: "Afinal, o que há, enfim, de tão perigoso no fato de as pessoas falarem e de seus discursos proliferarem indefinidamente? Onde, afinal, está o perigo?” (Foucault, 2012, p. 8), como um desdobramento de sua análise do discurso atravessada, agora, pelo poder. Esse atravessamento do saber pelo poder levará a um deslocamento na noção de episteme, enquanto produção de saberes, para a emergência da noção de dispositivo, sem que episteme seja abandonada. Ao autor interessa explicitar como os dispositivos de poder, dispostos no cotidiano, na microfísica, possibilitam a produção de enunciados tidos como verdadeiros (Foucault, 2012). Assim, o dispositivo encontra-se, segundo o autor "sempre inscrito em um jogo de poder, estando, sempre, no entanto, ligado a uma ou a configurações de saber que dele nascem, [e consiste] em estratégias de relações de força sustentando tipos de saber e sendo sustentadas por eles" (Foucault, 1979, p 246).

O dispositivo é a rede de relações que se estabelece entre "um conjunto decididamente heterogêneo que engloba discursos, instituições, organizações arquitetônicas, decisões regulamentares, leis, medidas administrativas, enunciados científicos, proposições filosóficas, morais, filantrópicas” (Foucault, 1979, p. 244). Nesses termos, entende-se o “dispositivo" como um operador metodológico que nos auxilia na análise das práticas discursivas, de poder e de subjetivação, proposta deste artigo.

A incidência das relações de sujeitos advindos de diferentes classes e com atravessamentos políticos distintos torna a sala de aula uma potência dirigida à abertura das margens. O docente pode, então, estar aberto ao alargamento dos conhecimentos e das possibilidades de intervenção ou fechado à reprodução do instituído no campo do verdadeiro. De qualquer forma, mesmo contra os empenhos do educador mais conservador, outros desenhos podem surgir a partir das linhas traçadas em sala de aula e a criatividade, a transgressão e os posicionamentos reformulados por cada sujeito geram campos de problematização e de transformação das subjetividades compostas nas/pelas ações pedagógicas. Assim, glosamos a percepção da função-educador, uma expansão da funçãoautor, apresentada e discutida com maior propriedade por Carvalho (2011).

Valem aqui algumas ressalvas, as IES (Instituição[ões] de Ensino Superior) componentes de nossa amostragem se dividem, em relação ao mandante institucional, em quatro categorias: públicas, confessionais, comunitárias e privadas. Consideramos, de acordo com Guilhon Albuquerque, que "O mandante é o ator individual ou coletivo, diante do qual, a instituição responde, ou em nome de quem ela age, e em geral se trata de outra instituição e, mais comumente ou em última instância do Estado" (1978, p. 73). As implicações dessas categorias nas atividades pedagógicas são contundentes, pois marcam a legitimidade da 
proposta institucional na construção da subjetividade de seu objeto ou na produção de um sujeito dobradiça (Guirado, 2010, p.155). O sujeito dobradiça marca, como metáfora, uma posição subjetiva na qual as marcas da singularidade se implicam com o discurso institucional tendo como efeito um sujeito identificado aos traços da formação na qual se inseriu e pelas quais se reconhece.

Assim, grosso modo, uma instituição privada é marcada pela lucratividade que deve garantir seu sustento, a reprodução de suas condições de existência e a satisfação de seus proprietários ou acionistas. As universidades confessionais se caracterizam pela proposta de manter viva e eternizar um conjunto de valores ligados a uma instituição religiosa, tal qual a IES comunitária investe na comunidade. Essas duas podem ser lucrativas, mas como não têm o caráter financeiro como objetivo final se comprometem a reinvestir em si mesmas os lucros obtidos. A universidade pública responde ao Estado (e não ao governo como se faz crer ultimamente). Seu compromisso é com a construção de uma sociedade nacional ou, mais agudamente, tem suas atividades voltadas para que o sujeito nela formado desenvolva esforços à produção de um modelo de Estado.

Nesse sentido, a universidade pública não forma o sujeito para si mesmo, para a realização pessoal ou para o mercado, mas forma para que seja um trabalhador que torne o Estado mais eficiente. As universidades confessionais e comunitárias não formam sujeitos com compromissos definidos a priori, este sujeito pode ser, portanto, um artista, um artesão, um profissional autônomo ou um funcionário, mas em qualquer ponto social que desempenhe, presumivelmente, manterá alguma lealdade aos valores que o tornaram um profissional pleno. Por fim, a universidade privada tem em seu discurso os traços de que, como qualquer comércio, ela própria precisa do lucro e a formação dos egressos, por consequência, carrega as marcas do empreendedorismo, do pensamento neoliberal, o que significa que o sujeito deve tornar-se, ele mesmo, uma empresa: vender-se, lucrar consigo mesmo, ter um marketing pessoal etc.

Abro um pequeno parêntese para inserir a questão neo-liberal no âmbito da racionalidade, de como a sociedade se representa. Assim a retiramos dos enquadres ideológicos e a dispomos na lógica da concorrência, do produtivismo e das altas performances que se encontram, embora de maneiras diferentes, na regulação das relações que se orientam para o princípio da máxima economia e da diminuição dos custos do Estado (Foucault, 2008).

Há, evidentemente, em períodos de crises econômica e moral, como os que vivemos hoje, algumas variações de comportamento institucional que podem gerar alguma confusão. Assim, uma instituição comunitária ou confessional pode agir em função de sua sobrevivência financeira, o que não significa que os limites dessa atuação ou as tensões internas permaneçam alienadas de seus valores. Feitas as ressalvas, retornemos às considerações institucionais. Universidades Públicas não estão isentas dos movimentos de dirigirem-se ao mercado como padrão para seu funcionamento, Bianchetti e Sguissardi (2017) apontam como o modelo de commodities, a commoditycidade, atinge a Educação e a sacrifica impondo a formação mercantil, econômica e massificada como alternativa para um 
sujeito-mercado alcançado pelo discurso de que este é o caminho para uma sobrevivência mais digna no mundo do trabalho atual.

Nesse contexto, o docente é um agente institucional e há diferenças em seu exercício profissional na relação com o mandatário. Para exemplificar vamos expor os regimes de contratação funcional. Nas IES públicas o regime preferencial de contratação é o de efetivação de um servidor concursado para jornada integral e exclusiva ao cargo empossado e, caso ele não cometa faltas relativas ao seu desempenho, sua estabilidade é garantida. Essa regra permite a emergência de conflitos sobre diferenças político-ideológicas, a diversidade de posturas pedagógicas, o investimento em áreas que o mercado julga pouco viáveis devido a seus custos e retornos duvidosos (do ponto de vista financeiro) e o investimento em pesquisas e em projetos de extensão que só interessam ao Estado. Essa condição produz possibilidades de atuação em relação ao tipo de trabalho e à distribuição do tempo em atividades de ensino, pesquisa e extensão, além das atividades administrativas que permitem aos professores um conhecimento mais apropriado da instituição onde trabalha e, torna-se, ele mesmo, um construtor ativo de seu posto de trabalho como membro de colegiado das esferas decisórias e estratégicas organizacionais.

Há, no universo das IES confessionais e comunitárias outros atravessamentos. Onde há pós-graduação stricto-sensu e contratação em regime integral, a maioria pode dedicar-se ao ensino e à pesquisa. No entanto, o exercício de atividades profissionais fora da vida acadêmica, em clínicas ou consultorias, mantém bom número de professores simultaneamente em atividades típicas do cotidiano de um profissional autônomo, consequentemente mais próximo ao que os estudantes projetam como futuro. Lembramos, porém, os regimes de mercado que envolvem as IES apontam a tendência geral de massificação do ensino e de banalização da produção científica.

As IES privadas, transnacionais principalmente, cumprem minimamente o que permite sua permanência no mercado (Macedo, 2017). Isso implica na contratação de professores habilidosos em agradar seu aluno-cliente. Como o regime de contratação é majoritariamente por horas trabalhadas, muito frequentemente admite um trabalhador que atua em um segmento específico do mercado para trabalhar, no contraturno, em sala de aula. Essa combinação de atividades, quando agrada a todos, estabiliza esse profissional como docente. Se onde esse profissional atua fora da IES recebe alunos para estágios ou se ele trabalha também como supervisor de estágios, traz para o interior de seu curso uma parte expressiva de sua realidade profissional.

Entre as condições de produção dos docentes observamos posições opostas: os docentes das IES públicas, em regime de Dedicação Exclusiva, têm interditada a prática profissional fora da academia e a pesquisa e a extensão devem suprir as faltas provocadas por essa restrição; já os profissionais que são docentes no contraturno ganham com suas experiências cotidianas, mas não reúnem condições para o desenvolvimento de pesquisas e extensões sistemáticas.

Para avançarmos na análise das condições institucionais de emergência de um professor de Psicopatologia, apresentamos os procedimentos de acesso aos dados e damos as diretrizes da constituição do recorte de nossa amostragem. Ao descrevermos a amostra, apontamos as 
circunstâncias históricas geopolíticas, trabalhistas e econômicas que delineiam a existência de um sujeito que poderia ser definido como professor formador de psicólogos ou como professor de Psicopatologia.

Por fim, tentamos indicar a organização deste lugar como uma territorialização de políticas públicas de Saúde, Educação e Segurança atreladas aos interesses de governo ou de mercado que marcam este conhecimento como parte do agenciamento biopolítico no controle das populações.

\section{Navegação Dirigida: Mapas, Correntes e Portos Acadêmicos}

O recorte que desenvolvemos aqui nos demandou um contato com dados públicos documentais de docentes que atuam em sala de aula de Psicopatologia, recorremos então à plataforma lattes. Há, entretanto, centenas de cursos de graduação no país e nossa amostragem busca atentar para a diversidade geopolítica - variável valorosa no campo Educacional -.

Optamos pelos meios eletrônicos para coletar os dados e o fizemos até próximo ao limite das possibilidades. Nossa navegação foi realizada pela internet, primeiramente por meio da plataforma $e-M e c$, para localizar os cursos. Nosso plano de trabalho continha as diretrizes da representatividade e da proporcionalidade e o critério da acessibilidade para a seleção. A acessibilidade digital como critério de amostragem foi derivada da "Amostragem por acessibilidade ou por conveniência”, conforme exposta por Gil (1999, p. 104).

Desta forma, cada unidade da federação foi acessada, via $e-M e c$, em ordem alfabética. Colocamos como termo de busca o curso Psicologia nas modalidades Bacharelado e em andamento. Apontado o curso, procurávamos sua página eletrônica e nela seu corpo docente. Assim, chegávamos ao currículo Lattes dos docentes e caso fosse inacessível, passávamos para a IES seguinte apresentada pela plataforma $e-M e c$.

Por representatividade compreendemos que a amostragem se comporia por cursos de IES privadas, públicas e confessionais ou comunitárias, logo, três grupos foram formados. Para nos aproximar da proporcionalidade, elencamos um número mínimo de cursos por região, assim chegamos a 7 IES públicas e gratuitas, sendo 6 federais e 1 estadual, 7 confessionais, 1 comunitária e 36 particulares. O acesso aos dados das IES públicas é aberto, o que facilita acessar os dados e, em contraste, as IES particulares não tornam seus dados disponíveis, com poucas exceções. Esse foi um dos limites da amostragem: as páginas eletrônicas de muitas IES particulares funcionam como plataforma de vendas e não como informativo do funcionamento institucional ou de seus cursos. Essa dificuldade revela o caráter comercial no primeiro plano: descontos no preço, financiamentos acessíveis e benefícios aos alunos são destacados no meio virtual.

Com os currículos selecionados, partimos para uma observação dos seguintes dados: formação acadêmica, tempo de graduação, titulação máxima e tempo dessa titulação, área da titulação, tempo e regime de contratação, produção acadêmica (artigos, livros, capítulos de livro, projetos de pesquisa, orientações, atividades de extensão, atividades administrativas...) 
disciplinas lecionadas e outros trabalhos. Como meio de organização, fizemos registros de distribuição de eventos e de peculiaridades regionais.

Após os registros descritivos, procuramos apontar algumas condições discursivas constituintes dos lugares ocupados pelos professores e as imagens que as gramáticas provocam na subjetividade e nas representações dos sujeitos postos nestes maquinários.

\section{Dados descritivos: há um Docente em Psicopatologia?}

Há um pressuposto na pergunta que dirige este item: deve haver um professor de Psicopatologia. É um pressuposto disciplinar cuja existência indica um saber distinto dos demais no campo Psi. Aqui, entretanto, buscamos não centrar na separação do conhecimento em disciplinas nem na compreensão de que o valor das especificidades conceituais, históricas, clínicas, sociais ou filosóficas de um campo qualquer indiquem um saber superior aos demais fundamentos para a formação em Psicologia.

Nosso estudo investiga exclusivamente cursos de Psicologia e certamente esse recorte profissional constitui um viés. Historicamente, o estudo da Psicopatologia se inicia como abordagem à loucura e na medida em que a modernidade avança e a racionalidade científica se apropria dos objetos a loucura vai se deslocando do império religioso para o da moral social e com a institucionalização médica vinculada à gestão biopolítica vai se caracterizando como um tema da Saúde Mental, ligado à Medicina. A Pedagogia e a Psicologia se associam à proposta de firmar a Saúde como efeito da boa educação e tornar seus desvios tratáveis pela terapêutica clínica ou evitáveis pelos métodos preventivos como o da higiene mental. Logo, a Psicopatologia integra as políticas de formação com vistas à distribuição de tarefas políticas dirigidas ao controle da sociedade.

\section{Formação Acadêmica}

Figura 1 - Formação acadêmica - Graduação

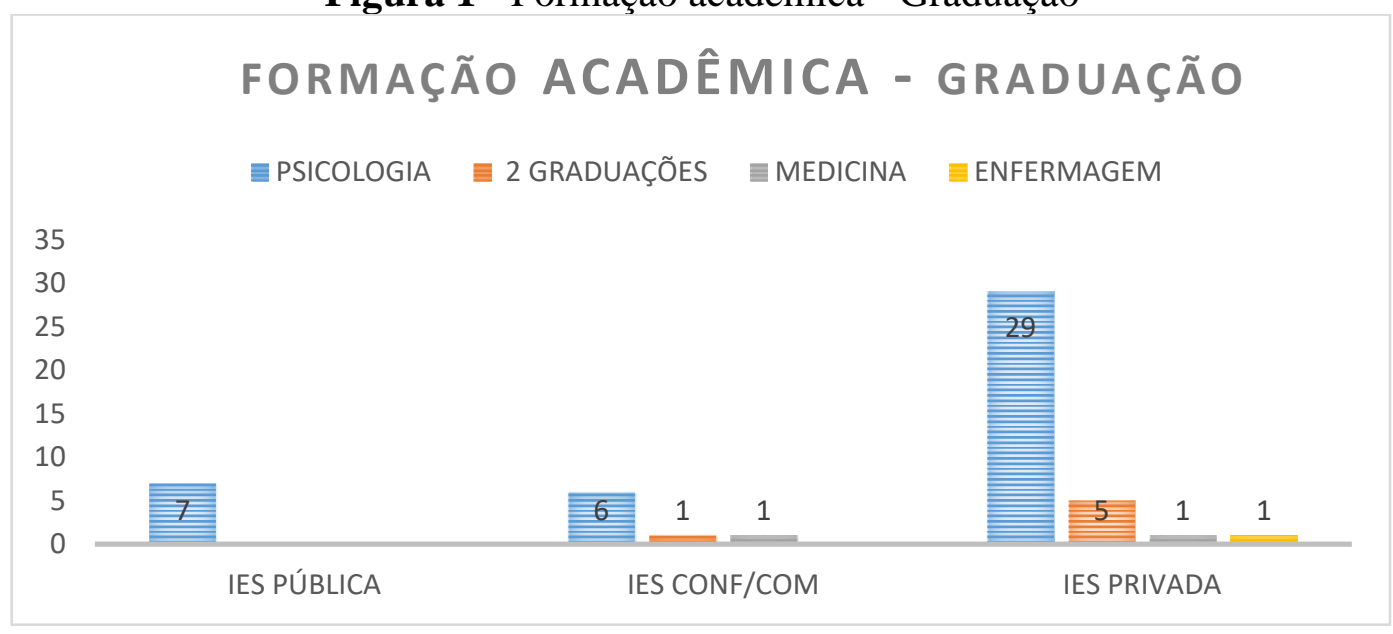


Este gráfico mostra a preponderância da graduação em Psicologia entre os professores. A pequena variação aponta a Medicina e a Enfermagem como graduações alternativas, o que significa uma tendência à inclusão da disciplina Psicopatologia no rol da Saúde. Mais que isto, indica uma preferência como se a identidade profissional assegurasse um valor indissociável à disciplina. A Psiquiatria, como especialidade da Medicina, e a Enfermagem Psiquiátrica certamente se associam a esse campo pelas suas interfaces com a clínica e com a saúde mental, ou ainda pelo poder social da linguagem médica. Os docentes com duas graduações conjugam Filosofia, Letras, Pedagogia, Educação Física ou Administração de Empresas com a Psicologia.

Figura 2 - Formação acadêmica - Titulação Máxima Concluída

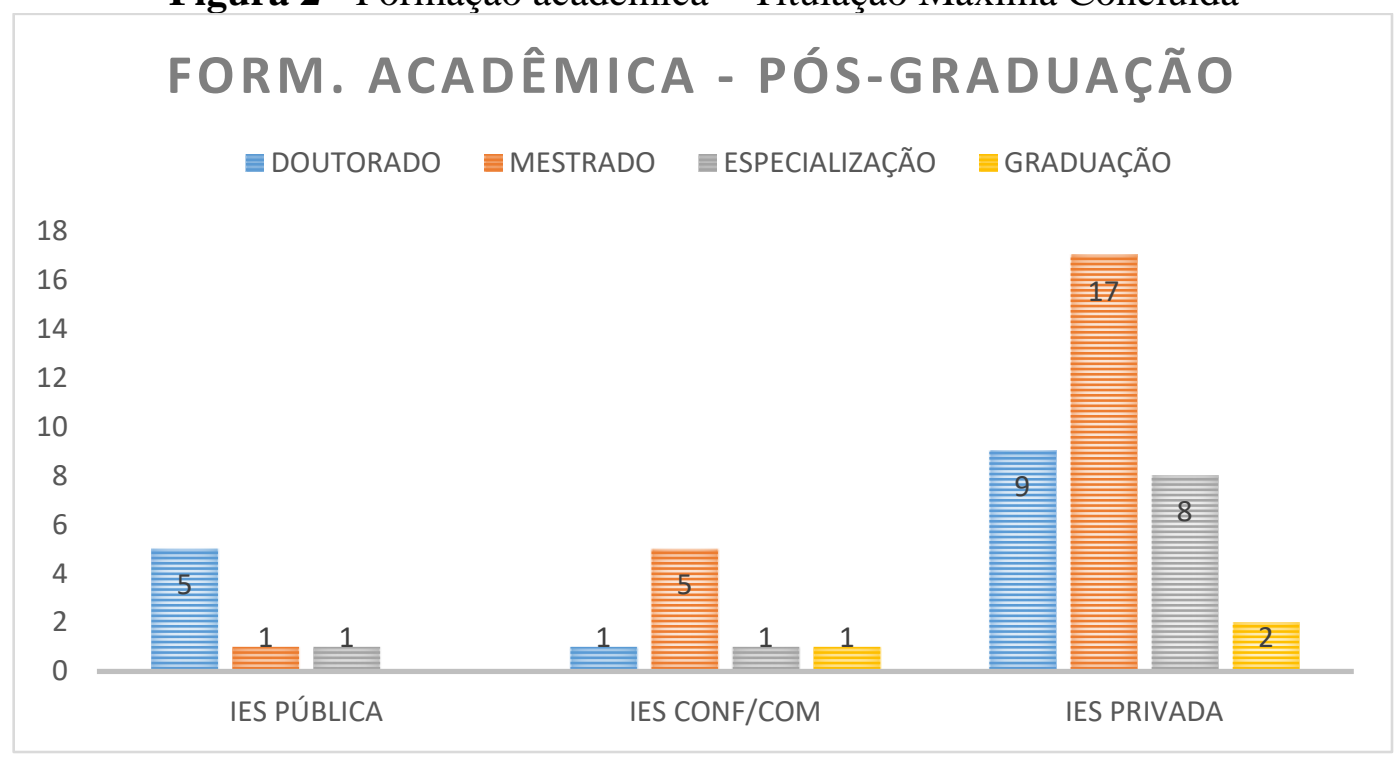

Se por um lado a graduação deste docente provoca um efeito de identidade - psicólogos ensinando psicólogos -, por outro lado, em sua pós-graduação, emerge um reflexo da diversidade de saberes constitutivos da Psicopatologia. Os docentes possuem variados percursos ampliando o leque das áreas das graduações conjugadas que se repetem na pósgraduação. Temos especialistas nas áreas de Psicobiologia, Neuropsicologia, Terapia Cognitivo Comportamental, Psicologia Clínica, Psicanálise, Psiquiatria, Saúde Mental, Saúde Pública e Saúde Coletiva.

Quanto ao grau de formação nas IES privadas e também nas comunitárias e confessionais há muitos professores cuja maior titulação é a de mestre. Assim, são 17 mestres (de 36 docentes no total) nas IES privadas e 5 (do total de 8) nas confessionais ou comunitárias. Nas IES públicas há apenas um mestre. Os mestres são das áreas de Educação Especial, Psicologia da Saúde, Letras (Linguística), Desenvolvimento Humano, Ciências e Sociedade, Ciências da Saúde, Saúde Coletiva, Psicanálise, Filosofia e Envelhecimento Humano. Os professores com doutorado se concentram nas IES públicas, dos 7 selecionados na amostra 
há 5 professores com doutoramento em programas de pós-graduação em Saúde Pública, Educação, Filosofia, Ciências Médicas e Psicologia. Nas IES confessionais e comunitárias, em nossa amostragem, encontramos um doutor. Nas IES privadas encontramos 9 doutores, sendo 4 em Psicologia e os demais em Psicobiologia, Ciências, Linguística, Ciências da Saúde e Psicologia Clínica.

A formação variada pode ser tomada como um indicativo da interdisciplinaridade característica do campo Psicopatológico. Poderia ainda ser maior, basta ver a autoria de artigos científicos para observar sociólogos, antropólogos, farmacêuticos e historiadores produzindo nesse campo.

\section{Tempo e regime de contratação}

Para ampliar a possibilidade de compreensão da existência de um professor de Psicopatologia, vamos olhar o tempo de exercício no trabalho. É indubitável que as circunstâncias da estabilidade do servidor público compõem um quadro diferenciado de permanência para o professor efetivo. Os dados apontam, no entanto, algumas peculiaridades e representações contrárias aos discursos em circulação. Em relação às IES públicas, observamos que há professores com maior permanência nas instituições mais antigas, localizadas nas capitais, já nos cursos novos e localizados em campi distantes dos grandes centros há professores substitutos cujo contrato não pode ultrapassar dois anos. Logo, há nas IES antigas professores doutores em regime de dedicação exclusiva e com mais de 15 anos de trabalho e são estes que realizaram com maior frequência estágios pós-doutorais, participam de programas de pós-graduação, têm grupos de pesquisas e se comprometem com projetos de extensão articulados tematicamente com ensino e pesquisa. As condições das IES públicas - estaduais ou federais novas - são semelhantes às antigas, mas os dados nos permitem supor que encontram dificuldades na contratação imediata de professores efetivos com doutorado concluído.

Precisamos ponderar a existência de muitos cursos criados pelas IES privadas nos últimos anos. Mesmo assim, a média de tempo de contratação não é baixa, não há trocas com rápida ciclagem e os professores de IES privadas permanecem longos tempos em seus trabalhos. Em nossa amostragem, um terço desses professores tem mais de 10 anos de permanência. Alguns desses professores atuam em até 3 IES, na mesma disciplina e chegam a perfazer jornadas semanais de 44 horas em sala de aula. Outros trabalham em instituições públicas de Saúde Mental, de Assistência Social ou da Justiça. Temos ainda psicólogos clínicos, hospitalares, escolares e da Atenção Básica à Saúde. A maioria, no entanto, pode não se identificar como professores de Psicopatologia, mas são identificados como professores de outras disciplinas em cursos de Psicologia ou em outros cursos das áreas de saúde, educação ou administração. Nesse aspecto, os docentes da IES comunitárias e confessionais são muito semelhantes.

Dos 36 professores das IES privadas, 32 declaram o regime de contratação. Destes, 21 são contratados como horistas, apenas 3 em regime parcial e 8 em regime integral ou de dedicação exclusiva. Os que estão nessa última condição assumem também tarefas 
administrativas em suas IES, são coordenadores de curso, assessores da direção, coordenadores de clínica escola e coordenadores de pós-graduação, entre outros. O quadro nas IES confessionais e comunitárias também é semelhante. Há, entretanto, uma diferença: as contratações nas IES privadas são, majoritariamente, menores que 20 horas semanais e nas IES confessionais e comunitárias com jornadas maiores.

\section{Atividades e Produções acadêmicas}

Os docentes das IES públicas vivem exclusivamente das atividades acadêmicas e isso resulta em produção numericamente mais elevada. Breve levantamento realizado em 2 revistas científicas com temáticas voltadas à Psicopatologia e à Saúde Coletiva, em volumes publicados recentemente, apontou que aproximadamente $90 \%$ da produção de artigos científicos nacionais, nestas áreas, têm autores ligados às IES Públicas. A presença no corpo editorial também se aproxima disso. Há exceções, existem professores de IES privadas com larga produção, embora entre eles seja comum a frequência em grupos de pesquisa em IES públicas próximos aos seus trabalhos. Nas IES confessionais e comunitárias há, também, professores cuja produção se destaca. A produção de textos acadêmicos está mais ligada à participação em Programas de Pós-Graduação do que qualquer outro fator.

As atividades de orientação são também díspares. Nas IES onde há pós-graduação as orientações compõem a rotina docente, então, em grupos de pesquisa são orientadas teses, dissertações e monografias. Nas Universidades confessionais e comunitárias, 2 docentes atuam em cursos lato sensu e 2 em Residências, sendo 1 deles em Residência Multiprofissional em Saúde. Dos 36 docentes de IES privadas pesquisadas, 1 trabalha em programa stricto sensu e 5 em lato sensu e, ainda, alguns professores orientam dezenas de trabalhos de conclusão de curso (TCC). A distribuição irregular das orientações permite-nos supor que essa atribuição seja restrita ou que não seja registrada no currículo Lattes.

As IES privadas produzem muitas monografias e artigos, mas a publicação é rara. A variação temática das orientações destes TCC aponta para a escolha de um objeto de pesquisa da preferência do estudante e o orientador não elege temas prioritários. Essa prática parece ser uma resposta às exigências de realização de pesquisas, contudo não são práticas sistemáticas, eletivas e qualificadas pela capacitação dos grupos de pesquisa organizados e dirigidos às investigações coletivas, em rede e metodologicamente delineadas. Pratica-se, assim, uma escrita disciplinar restrita como uma espécie de ensino instrumental de pesquisa científica. Isso se repete nas IES confessionais e comunitárias. Nas IES públicas, além das orientações nos programas stricto sensu, há, para os graduandos, maior número de orientação à Iniciação Científica e o trabalho temático é preponderante.

O trabalho em sala de aula ou em supervisão de estágio assim se distribui: nas IES privadas, invariavelmente, os docentes assumem disciplinas e não são atribuídas horas para qualquer outra atividade acadêmica, sendo comum lecionarem 6 ou mais disciplinas por semestre. Com isso, vimos a possibilidade de algumas questões se tornarem incômodas aos docentes contratados como horistas: grande diferença semestral de horas trabalhadas desorganizando a distribuição do tempo e, também, a vida financeira e outros compromissos 
de trabalho ou estudo. Por fim, observamos o excesso de horas de trabalho, como o caso de um professor com mais de 10 disciplinas simultâneas, cuja jornada semanal era de 62 hs (40 hs diurnas, 14 hs noturnas, 8 hs aos sábados).

Os professores das IES privadas possuem, frequentemente, mais de um vínculo empregatício. Em nossa amostragem, 20 professores declaram outro trabalho simultâneo. Os trabalhos mais frequentes são no serviço público (Centros de Atenção Psicossocial, Centros de Referência de Assistência Social e Tribunais de Justiça, entre outros), apenas 3 apontam práticas clínicas e 8 são professores em mais de uma IES. Isso indica que existem mais professores formadores de psicólogos com múltiplas disciplinas do que professores de disciplinas específicas, como a Psicopatologia.

Curiosamente, entre as disciplinas e estágios atribuídos a esses professores, poucos são ligados aos serviços públicos, a maior parte é relativa às atividades da clínica privada, sendo a Análise do Comportamento a abordagem mais frequente, seguida da Psicanálise. Outras disciplinas recorrentes nos sugerem alguma proximidade com o que foi chamado de TEAP Técnicas de Exame e Aconselhamento Psicológico -no período da regência do currículo mínimo na formação.

Há também nas demais IES (públicas, confessionais e comunitárias) forte identificação da Psicopatologia com as atividades clínicas, com primazia da Psicanálise e supervisão de outros estágios clínicos. Também nessas IES os professores atuam tematicamente e as disciplinas sobre Técnicas ou Políticas de Intervenção são mais frequentes: violência, imigração, redução de danos, saúde coletiva, saúde mental, trabalho, etnopsicologia e segurança alimentar estão no rol de suas atividades de ensino, pesquisa e extensão. Destacamos aqui 3 projetos ligados às intervenções (inter)culturais. Nas IES confessionais e comunitárias não registramos a atuação em extensão nos últimos 3 anos.

Os docentes de IES públicas também realizam outros trabalhos. Quando externos às IES são ligados às associações universitárias de pesquisa e às agências de fomento e, quando internos, são coordenações de projetos como os de Educação Tutorial e Iniciação Científica.

\section{Atravessamentos discursivos: lugares e contextos políticos}

A amostra observada aponta a formação bastante hegemônica em Psicologia para essa função. Quando da criação dos primeiros cursos de graduação, na década de 1950, até o primeiro boom de oferta de cursos com a regulamentação da profissão e também da formação na década de 1960, os primeiros professores, presumivelmente, não eram psicólogos. O segundo boom, na década de 1990, com a agenda neoliberal, já contava com psicólogos para o exercício do magistério, sem, contudo, haver pós-graduação suficiente para a formação desses professores.

No momento atual acontece o terceiro boom. A proliferação em marcha se dá em cursos nas IES privadas e é estimulada por vários fatores, entre eles a abertura de financiamentos e a posição do mercado que valoriza a formação superior (Lisboa; Barbosa, 2009). No entanto, o professor ter concluído sua graduação em, no mínimo, 12 anos e, com maior frequência, há 
mais de 25 anos, em todas as modalidades de IES, indica a valorização social alçada para manter-se neste lugar predominantemente ocupado por Psicólogos. Esse dado formativo indica, também, um deslocamento do lugar da Psiquiatria para a Psicologia, firme e rapidamente - o que foi considerado uma conquista para a categoria dos psicólogos. Há cursos com disciplinas obrigatórias de Psicofarmacologia e Psiquiatria em suas matrizes curriculares, indicando uma presença residual dos saberes biomédicos e também a eventual permanência de professores médicos psiquiatras remanescentes dos anos 1970/80.

Reconhecendo as limitações de nossa pesquisa, arriscamos afirmar que o lugar da fala sobre a Psicopatologia nos cursos de Psicologia deslocou-se da prerrogativa da formação médica para ser tarefa compartilhada por Psicólogos e, como tal, consta, indiretamente, de nossas Diretrizes Curriculares Nacionais (CNE, 2004) como uma face da formação em Saúde. Esse movimento não se dá exclusivamente nos espaços de formação profissional e talvez seja um efeito das transformações do campo de trabalho onde se instalaram os equipamentos substitutivos da Reforma Psiquiátrica com as equipes de Saúde Mental assumindo papel relevante.

Mas esse dado da Política de Saúde Mental brasileira traz à baila outro aspecto que transita e alcança as subjetividades em nossas IES: o público e o privado em Psicopatologia. As IES públicas trabalham com docentes definidos como servidores públicos e seus egressos são atravessados por concepções de saúde em termos de construção coletiva, como notamos nos projetos de extensão por eles coordenados, com os temas: CRR - Centros Regionais de Referência sobre Drogas -, Rede de Atenção Psicossocial, Hiperdia, Violência nas Escolas e Intervenções Interculturais, entre outros. Os projetos de pesquisa também carregam as marcas das Políticas Públicas de Saúde e contemplam temas como Redução e Danos, Educação Inclusiva, Saúde de Agentes Comunitários de Saúde, Etnopsicologia e Imigração; por fim, promovem interfaces entre os campos originariamente calcados nas práticas da clínica privada que vêm atravessando as intervenções coletivas e públicas.

Há, no entanto, um direcionamento político inerente à atividade docente. Para além do público e do privado, existem outras formas de delinear o pensamento pedagógico que produzem dicotomias e essas dicotomias afastam a compreensão da existência de consequências sociais decorrentes tanto da forma como se concebe um campo profissional quanto das intervenções diretas sobre ele. Desse modo, o ensino é uma intervenção sobre as subjetividades presentes nas relações pedagógicas e essa intervenção não se restringe à sala de aula, desfazendo o discurso “aqui dentro" e "lá fora”, seja porque a sala de aula é transitória e composta por sujeitos sociais que transitam por outros lugares ou porque nela se discutem as instituições e políticas cujos objetos são focos dos trabalhos. As resistências, naturalmente, se manifestam em sala de aula e, seja em forma de oposição argumentada ou muda, produzem sempre outros discursos e marcam diferenças.

Outras dicotomias que assinalamos são as contraposições ilusórias postas entre o saber e o fazer que comportam formulações do tipo “a teoria na prática é outra”. Esse padrão de construção no qual incluímos as oposições de “conceitos versus métodos” e também de “ciência versus técnica” promove isolamentos de termos como se não fossem integrantes de uma mesma concepção de objeto. Em nossa perspectiva, a teoria é uma tentativa de 
sistematização coesa das formas de abordar um objeto, sendo a própria percepção mediada pela linguagem. Podemos, por esta abordagem, argumentar que a metodologia de um trabalho científico define seu objeto e, além disso, constrói uma trama que liga o objeto a outros objetos e saberes. Mas a linguagem é sempre incompleta e carregada de equívocos, de modo que, mesmo com a ilusão da completude e do controle sobre os objetos ou sobre a linguagem, a teoria produz sempre outras teorias com desdobramentos intermináveis, visto que nunca dá conta de seu objeto ou de seu trabalho (Foucault, 1979).

Apontamos uma das consequências dessas dicotomias na desvalorização das atividades práticas como se não houvesse um saber embutido no saber-fazer ou uma cognição implicada nos trabalhos manuais. E mesmo valorizando o trabalho intelectual, a dicotomia subsidia o pensamento de que o professor, sujeito do saber autorizado, seja alienado ao mundo das instituições concretas e não se implique em um fazer. Ainda assim, estamos todos marchando sobre um imaginário e o professor, seja pela via da construção abstrata ou pela via da intervenção nas instituições concretas, age sobre um conjunto de valores, saberes e práticas compartilhadas como verdades de nosso tempo.

Logo, para compor propostas de experimentos e avaliações de pesquisas ou para constituir um campo de aplicação de conhecimentos, as intervenções em atividades de extensão universitária e estágios se somam às práticas de sala de aula na função de validação e confirmação social do saber em construção. Contudo, essa via de validação é um recurso utilizado por professores extensionistas, supervisores de estágio ou por aqueles cujas atividades profissionais atendem diretamente as demandas sociais em esferas afins, como a Jurídica, a Assistência Social ou a Saúde Mental.

A atribuição de credibilidade ao ensino e ao conteúdo discutido pela disciplina, como em qualquer área, vem do reconhecimento do valor do saber nos campos de trabalho. Desta forma, os docentes de IES que desenvolvem pesquisas têm nos seus projetos de extensão um espaço de confirmação e as IES onde não se realizam pesquisas buscam o recurso de associar as atividades profissionais extra-classe de seus docentes. Assim, um profissional do tribunal de Justiça, da rede de Saúde Mental ou da Assistência Social utiliza como lastro pedagógico o reconhecimento da própria atividade profissional externa à IES.

Observamos que parte dos professores de IES particulares é profissional desses campos de trabalho, mas a maior parcela leciona outras disciplinas, seja nos cursos de Psicologia como professores de alguma abordagem teórica tal qual a Análise do Comportamento ou Psicanálise, ou nos campos de atuação como a Psicologia Jurídica, a Avaliação Psicológica, a Saúde Mental e a Clínica, entre outras, ou ainda em outros cursos das áreas de Saúde, Educação ou Administração, associando a Psicopatologia a outros discursos para apoio, complementação e validação de seus saberes. Assim, com frequência, encontramos docentes que se definem como professores de Psicologia e atuam em várias disciplinas, sendo frequente lecionar 5 ou 6 delas, podendo ultrapassar o trabalho em mais de 10 disciplinas simultaneamente.

Os discursos ligados ao Desenvolvimento, à Aprendizagem e à Psicopatologia se articulam com saberes administrativos, educacionais, de segurança e saúde e penetram outros discursos. A linguagem "psi”, como afirma Rose (1996; 2001), carrega em si as marcas da 
subjetivação e agencia a definição dos sujeitos em termos de força, criatividade, vinculação, motivação, sentimentos e sensações. E, com estas definições em termos Psico[pato]lógicos, os sujeitos são postos em relação consigo mesmos, na medida que os usam para se definirem socialmente, ou para a relação com os outros, na medida que são diagnosticados, classificados e até mesmo interditados por instituições de trabalho, trânsito, segurança etc, que realizam testes de aptidão ou admissionais.

O uso do conhecimento disciplinar, nesse sentido, diz respeito à política de condução dos indivíduos na medida em que interfere na vida de um sujeito dando-lhe ou rejeitando-lhe um trabalho, permitindo-o dirigir um automóvel ou ser portador legal de uma arma, mas a biopolítica trata dessas questões coletivamente, propondo, por exemplo, intervenções globais como a vacinação preventiva aos riscos de adolescentes contraírem uma doença sexualmente transmissível (Bittencourt, 2015), o uso de medicação para crianças hiperativas na idade escolar (Decotelli; Bohre; Bicalho, 2013) ou o uso de antidepressivos para as mulheres idosas (Rozenfeld, 2003).

A Psicopatologia se dispõe, então, como um eixo inegociável do dispositivo da Biopolítica por meio dos processos de categorização, normalização, ajustamento, medicalização, promoção e exclusão social e, para/com isso, se vincula aos dispositivos da governamentalidade. A construção histórica da gramática psicopatológica, com descontinuidades e conflitos, segue a direção da atenção às necessidades de controle das populações (Sathler, 2016, p. 78). A essa associação da biopolítica com as técnicas de controle das populações, resultantes dos agenciamentos na produção de subjetividades, Foucault (2003) chamou de governamentalidade, conceito que podemos ver como instrumento de análise em: Lopes e Dal'Igna (2012) ao discutirem a relação de gênero e inclusão, Lasta e Hillesheim (2014) ao abordarem as questões das anormalidades nas escolas, Cesar e Duarte (2017) ao analisarem as questões do corpo e da sexualidade nas propostas dos movimentos da Escola Sem Partido, e Santaiana e Forell (2017) que tratam da docilização das crianças nas propostas educacionais.

A produção e gestão das anormalidades pela exclusão ou pela docilização dos corpos tem uma história. Na Europa, na idade média, já existiam manicômios. Além dos chamados insanos, lá eram postos outros sujeitos indesejáveis como os criminosos e os vagabundos. Por volta do séc. XVIII, essas instituições, às vezes religiosas, às vezes privadas e, na Inglaterra, públicas e territorializadas, livravam seus sujeitos das condições degradantes dadas pelas famílias ou pelas aldeias. O iluminismo, entretanto, carregava consigo a ideia da cura e a medicina começou a gozar de algum prestígio com suas sangrias, purgas e eméticos. Nesse período, o governo, com sua engenharia social, política e médica, lança a proposta de um hospital para loucos que mesmo sem investir na cura buscava uma terapêutica centrada na institucionalização do paciente (Shorter, 2001). Assim, se estabeleceram inicialmente os tratamentos morais e, na sequência, as classificações psiquiátricas que devido à possibilidade de observação sistemática dos internos, alcançaram o lugar de diagnósticos médicos.

Mais adiante, um pouco menos como controle da população e um pouco mais na busca de tratamentos, simultaneamente e em localidades muito próximas, com centro nos países de língua alemã, se desenvolvem a Psicopatologia Fenomenológica, a Psicologia, a Psicanálise 
e a Psiquiatria Biológica. Com isto, as explicações e as propostas terapêuticas se ampliaram, inserindo as intervenções clínicas individuais.

Intervenções clínicas hospitalares, coletivas e individuais de naturezas distintas são produzidas ao final do séc. XIX e início do séc. XX. Logo após a II guerra se firmam movimentos de retorno à comunidade, entre estes movimentos a Anti-Psiquiatria se destaca e a Psicofarmacologia se estabelece com medicações que alteram o funcionamento do humor, do pensamento e da percepção, preservando a consciência (Shorter, 2001).

Desta forma, um arcabouço amplo de saberes e práticas se acumulam na perspectiva do controle de comportamentos em busca da docilização, obediência e produtividade. Associam-se a essas produções o maquinário neoliberal que com seu ideário produz sujeitos de alta performance com seus sofrimentos (Birman, 2014).

A sobreposição dos dispositivos da governamentalidade: políticas de controle do tempo, modelos diagnósticos, práticas interventivas, concepções de subjetividade, classificações de pessoas e políticas públicas de atenção à saúde das populações compõem atravessamentos discursivos que constituem o lugar do profissional do comportamento e da Psicopatologia que trata dos desvios normativos. Além disso, tópicos filosóficos como o da natureza do normal e anormal, da saúde e doença, temas sociais contemporâneos como drogas, medicalização, violência, hiperconsumo, relações virtuais, abordagens psicossociais, métodos clínicos, relações de gênero e interculturais, entre tantas outras questões, compõem o campo Psicopatológico que se apresenta, então, em configurações que permitem entradas pelas vias coletivas, individuais, históricas e classificatórias nesse campo de saberes (Sathler, 2017).

Os docentes, orientados institucionalmente e voltados aos mandatários institucionais, elegem, com maior ou menor resistência, seus temas prioritários mostrando lealdade aos planos de governo aos quais se afinam ou se amparam nos planos mais viáveis econômica ou temporalmente que provocam financiamentos, viabilizam mais publicações ou respondem às questões locais mais emergentes para sustentarem suas carreiras ou, seguindo regras mais imediatas, focando a empregabilidade dos egressos, emparelhando-se aos discursos jurídicos, médicos, administrativos e escolares, inseridos nos discursos de mercado.

\section{Considerações Finais}

Com esse texto observamos as possibilidades do exercício da docência em Psicopatologia nos cursos de Psicologia em todas as regiões do país, em IES escolhidas segundo características de seus mandatários institucionais: públicas, particulares, confessionais e comunitárias, e nelas procuramos identificar as condições de produção do magistério ligadas aos regimes de contratação, às atribuições de atividades voltadas ao ensino, à pesquisa, à extensão e à administração, bem como aos trabalhos realizados fora da academia.

Nessa observação, vimos que há lógicas que sustentam não somente as práticas docentes, mas também as instituições de ensino: a primeira diz respeito ao egresso que se deseja formar 
e a segunda diz das linhas que sustentam as práticas pedagógicas. Destacamos, a seguir, alguns resultados.

Os docentes de Psicopatologia são graduados majoritariamente em Psicologia, mas têm pós-graduações em diversas áreas e, aqui, apresentamos apenas as áreas de concentração nos doutorados: Psicologia, Saúde Coletiva, Filosofia, Educação, Linguística, Ciências da Saúde e Ciências Médicas. Identificamos, porém, que os doutores estão preferencialmente nas IES públicas e a titulação prevalente na IES confessionais e comunitárias é a de mestre, o que compõe também praticamente a metade dos professores das IES particulares em que a outra metade se divide entre doutores e professores com titulação máxima de especialista.

Em todas as modalidades institucionais há um quadro de professores de Psicopatologia com longa permanência. Há um viés nesta leitura - o tempo de existência dos cursos - visto que grande número de IES particulares entrou em funcionamento há menos de 10 anos. Mesmo assim, na média a permanência se dá por mais de 10 anos.

Nas IES públicas há estabilidade no contrato, logo os professores permanecem em seus cargos por longo tempo, mas, a julgar pela titulação e pelo regime de contratação de professores substitutos, notamos que aquelas distantes dos grandes centros e criadas na última década encontram dificuldades na contratação de doutores para seus quadros. Embora tenhamos professores admitidos por concursos públicos em IES confessionais e comunitárias, vimos que a maioria deles é contratada pelo regime de horas trabalhadas. Levantamos a hipótese de que nas IES particulares, principalmente, se construam outras estratégias para permanência de seus quadros profissionais.

As estratégias de manutenção dos quadros profissionais se articulam às estratégias de reconhecimento do desempenho docente. Há sinais de que estar, simultaneamente, em atividade docente e no mercado de trabalho profissional, seja com sucesso como autônomo ou com aprovação em concurso público, dá certa credibilidade ao profissional. Além disso, lecionar a mesma disciplina em outras instituições, outras disciplinas no mesmo curso ou disciplinas afins em outros cursos compõem também estratégias de confiabilidade, o que é muito frequente. Evidentemente, junto com essas estratégias há a sobrevivência no mercado das IES particulares: o professor deve ser capaz de agradar seu cliente como em qualquer mercado competitivo.

A posição subjetiva ocupada pelo docente se faz na rede de atravessamentos deste lugar e os compromissos delineados pelos mandatários institucionais, as condições concretas do exercício do papel docente e a preparação acadêmica de cada professor se articulam numa plataforma que lança o docente numa carreira na qual deve dar respostas aos dispositivos biopolíticos da governamentalidade que reclamam sua inserção. Assim, seja pela via da produtividade acadêmica ou pelas estratégias não-acadêmicas de credibilidade ao papel de professor, temas como: drogas, medicalização, classificações nosográficas, violência, políticas públicas de Saúde Mental, de Assistência Social e de Segurança se fazem presentes para tornar este lugar reconhecido.

Outra fonte de confiabilidade comumente vista que sustenta o lugar do professor de Psicopatologia é a associação a campos de atuação profissional correlatos como hospitalar, escolar ou assistencial na Atenção Básica à Saúde, nos quais os conhecimentos em 
Psicopatologia são ferramentas para um desempenho técnico mais seguro. Então, nestes casos, temos um professor formador de Psicólogos envolvido com uma atividade profissional que tem algo a dizer aos seus alunos sobre a Psicopatologia observada em seu campo de atuação.

\section{Referências}

BERLINCK, Manoel Tosta. O ensino da psicopatologia: problemas e perspectivas. São Paulo. Pulsional Revista de Psicanálise. n. esp; maio, 2005. p. 166-178.

BIANCHETTI, Lucídio; SGUISSARDI, Valdemar. Da Universidade à Commoditycidade: ou de como e quando, se a educação/formação é sacrificada no altar do mercado, o futuro da universidade se situaria em algum lugar do passado. Campinas: Mercado das Letras, 2017.

BIRMAN, Joel. Drogas, performance e psiquiatrização na contemporaneidade. Ágora (Rio J.), Rio de Janeiro, v. 17, n. spe, p. 23-37, ago. 2014. Disponível em: $<$ http://www.scielo.br/scielo.php?script=sci_arttext\&pid=S151614982014000300003\&lng=pt\&nrm=iso>. Acesso em 08 abr. 2018. http://dx.doi.org/10.1590/S151614982014000300003.

BITTENCOURT, Naiara Andreoli. A biopolítica sobre a vida das mulheres e o controle jurídico brasileiro. Gênero \& Direito. Joao Pessoa. v.4, n. 2, p. 225-245, 2015. Disponível em: <file:///C:/Users/UserPc'/Downloads/25963-57865-1-PB.pdf>. Acesso em 07 maio 2018.

CARVALHO, Alexandre Filordi de. Função-Educador: em busca de uma função intercessora a favor das experiências de subjetividades ativas. In: RESENDE, Haroldo de. MICHEL FOUCAULT: transversais entre educação, filosofia e história. Belo Horizonte: Autêntica, 2011. P. 9-23.

CESAR, Maria Rita de Assis; DUARTE, André de Macedo. Governamento e pânico moral: corpo, gênero e diversidade sexual em tempos sombrios. Educ. rev., Curitiba, n. 66, p. 141-155, dez. 2017. Disponível em $<$ http://www.scielo.br/scielo.php?script=sci_arttext\&pid=S0104-

40602017000400141\&lng=pt\&nrm=iso>. Acesso em 07 maio 2018. http://dx.doi.org/10.1590/01044060.54713.

CNE. Conselho Nacional de Educação. Resolução nº 8, de 7 de maio de 2004. Institui as Diretrizes Curriculares Nacionais para os Cursos de Graduação em Psicologia. Diário Oficial da União, Seção 1, 16-17, 18 maio 2004. Disponível em: <http:// portal.mec.gov.br/cne/arquivos/pdf/rces08_04.pdf>. Acesso em 08 maio 2018.

DECOTELLI, Kely Magalhães; BOHRE, Luiz Carlos Teixeira; BICALHO, Pedro Paulo Gastalho de. A droga da obediência: medicalização, infância e biopoder: notas sobre clínica e política. Psicol. cienc. prof., Brasília, v. 33, n. 2, p. 446-459, 2013. Disponível em $<$ http://www.scielo.br/scielo.php?script=sci_arttext\&pid=S1414-

98932013000200014\&lng=pt\&nrm=iso>. Acesso em 07 maio 2018. http://dx.doi.org/10.1590/S141498932013000200014.FOUCAULT, Michel. A arqueologia do saber. 4a ed. Rio de Janeiro: Forense Universitária, 1995.

FOUCAULT, Michel. A ordem do discurso: aula inaugural no Collège de France, pronunciada em 2 de dezembro de 1970. São Paulo: Loyola, 2012.

FOUCAULT, Michel. Os intelectuais e o poder: conversa entre Michel Foucault e Gilles Deleuze. In: Microfísica do poder. Rio de Janeiro: Graal, 1979. p 69 - 78.

FOUCAULT, Michel. Sobre a História da Sexualidade. In: Microfísica do poder. Rio de Janeiro: Graal, 1979. p $243-276$ 
FOUCAULT, Michel. A Governamentalidade[1978]. In: Rio de Janeiro: Forense Universitária, 2003. p. 281 - 305.

FOUCAULT, Michel. Nascimento da Biopolítica. São Paulo: Martins Fontes, 2008.

GUILHON ALBUQUERQUE, J.A. Metáforas da desordem: o contexto social da doença mental. Rio de Janeiro: Paz e Terra, 1978.

GUIRADO, M. A análise institucional do discurso como analítica da subjetividade. São Paulo: Annablume, 2010.

LASTA, Leticia Lorenzoni; HILLESHEIM, Betina. Políticas de inclusão escolar: produção da anormalidade. Psicol. Soc., Belo Horizonte, v. 26, n. spe,p. 140-149, 2014. Disponível em $<$ http://www.scielo.br/scielo.php?script=sci_arttext\&pid=S0102-

71822014000500015\&lng=pt\&nrm=iso>. Acessos em 07 maio 2018. http://dx.doi.org/10.1590/S010271822014000500015 .

LISBOA, Felipe Stephan; BARBOSA, Altemir José Gonçalves. Formação em Psicologia no Brasil: um perfil dos cursos de graduação. Psicol. cienc. prof., Brasília, v. 29, n. 4, p. 718-737, 2009. Disponível em $<$ http://www.scielo.br/scielo.php?script=sci_arttext\&pid=S141498932009000400006\&lng=pt\&nrm=iso>. Acessos em 23 abr. 2018.

LOPES, Maura Corcini; DAL'IGNA, Maria Cláudia. Subjetividade docente, inclusão e gênero. Educ. Soc., Campinas, v. 33, n. 120, p. 851-867, set. 2012. Disponível em $<$ http://www.scielo.br/scielo.php?script=sci_arttext\&pid=S010173302012000300011\&lng=pt\&nrm=iso>. Acesso em 07 maio 2018. http://dx.doi.org/10.1590/S010173302012000300011.

MACEDO, Joao Paulo et al . Transnacionalização do Ensino Superior: Impactos nos Processos Formativos em Psicologia no Brasil. Psicol. cienc. prof., Brasília, v. 37, n. 4, p. 852-868, dez. 2017. Disponível em $<$ http://www.scielo.br/scielo.php?script=sci_arttext\&pid=S1414-

98932017000400852\&lng=pt\&nrm=iso>. Acesso em 09 maio 2018. http://dx.doi.org/10.1590/19823703004272016.

ROZENFELD, Suely. Prevalência, fatores associados e mau uso de medicamentos entre os idosos: uma revisão. Cad. Saúde Pública, Rio de Janeiro, v. 19, n. 3, p. 717-724, jun. 2003. Disponível em $<$ http://www.scielo.br/scielo.php?script=sci_arttext\&pid=S0102-

311X2003000300004\&lng=pt\&nrm=iso>. Acessos em 07 maio 2018. http://dx.doi.org/10.1590/S0102311X2003000300004.

SANTAIANA, Rochele da Silva; FORELL, Leandro. Ensino fundamental de nove anos: das estratégias do governo dos infantis nas políticas educacionais. Cad. CEDES, Campinas, v. 37, n. 102, p. 179-200, ago. 2017. Disponível em <http://www.scielo.br/scielo.php?script=sci_arttext\&pid=S010132622017000200179\&lng=pt\&nrm=iso>. Acesso em 07 maio 2018. http://dx.doi.org/10.1590/cc010132622017173869.

SATHLER, Conrado Neves. Formações subjetivas: o sujeito à luz da teoria dos discursos. Dourados, MS: EdUFGD, 2016.

SATHLER, Conrado Neves; MARTINS, Catia Paranhos; ABÍLIO, Elenita Sureke. Tendências pedagógicas do ensino de psicopatologia nos cursos de graduação em psicologia. Interdisciplinary Journal of Health Education, Belém, v.2, n.1, p 61-67, jun. 2017. Disponível em: $<$ https://ijhe.emnuvens.com.br/ijhe/article/view/286/31>. Acesso em $07 \quad$ maio 2018. DOI:10.4322/ijhe.2016.026.

SHORTER, Edward. Uma historia da Psiquiatria: da era dos manicômios à idade do Prozac. Lisboa: Climepsi, 2001.

VEIGA-NETO, Alfredo. O sujeito [cap. 7]. In: 2007. P. 107-115. Foucault \& a Educação. Belo Horizonte: Autêntica, 


\section{Correspondência}

Conrado Neves Sathler: É vinculado à Universidade Federal da Grande Dourados.

E-mail: c.sathler@uol.com.br

Márcia Aparecida Amador Mascia é vinculada à Universidade São Francisco - Pós-Graduação em Educação.

E-mail: marciaaam@uol.com.br

Texto publicado em Currículo sem Fronteiras com autorização dos autores 